\title{
ANTI-TRYPANOSOMAL ACTIVITY OF CRUDE AND NANO-CONJUGATED ETHANOL STEM BARK EXTRACTS OF Sterculia setigera IN MICE
}

\author{
${ }^{1}$ Abdulrazaq, M. 0., ${ }^{1}$ Adeyemi, H. Y., ${ }^{2}$ Abdulkareem, A. S., ${ }^{3}$ Bankole, M. T. and \\ *1Abubakar, A. \\ ${ }^{1}$ Biochemistry, ${ }^{2}$ Chemical Engineering, ${ }^{3}$ Chemistry Departments, Federal University of Technology, \\ Minna, Nigeria \\ *Corresponding Author: 08035895490; abukadir2@gmail.com or abdul.abu@futminna.edu.ng
}

\section{ABSTRACT}

This study was carried out to screen for anti-trypanosomal activities of Sterculia setigera crude and nano-conjugated ethanol extracts of synthesized gold nanoparticles (AuNPs). Fresh stem bark of $S$. setigera was separately extracted with ethanol (ES) and aqueous (AS) followed by green synthesis/reduction of ethanol extract with AuNPs, and its formulation into nano-conjugate with the addition of standard drug Diminazine aceturate (berenil). The synthesized AuNPs were also characterized. Both the extracts and drug were separately administered to Trypanosoma brucei brucei infected animals orally at $200 \mathrm{mg} / \mathrm{kg}$ bodyweight for 12 consecutive days. Two separate groups were infected untreated and infected treated with Diminazine aceturate (Berenil) to serve as positive and negative controls respectively. Similarly nanoconjugates of $S$. satigera and berenil were also orally administered to different groups of rats for 12 days consecutively. The results showed that the ethanol extract treated group recorded significant decrease in parasitaemia than the aqueous treated group when compared with the untreated control groups $(p<0.05)$. Furthermore, treatment with both the nanoconjugates effectively cleared the parasites from the blood circulation of the infected animal $(p<0.05)$. Bodyweight and PCV of treated groups improved significantly in all the treated animals $(p<0.05)$. The ethanol extract of $S$. setigera exhibited trypanostatic activity while its nano-conjugated was trypanocidal.

Keywords: Nanotechnology, Gold nanoparticles, Sterculia setigera, Antitrypanosomal, Nanoconjugated, Parasitaemia.

\section{INTRODUCTION}

One of the neglected tropical infectious diseases that affect human and animal, transmitted by the bite of tsetse flies, African trypanosomiasis, is prevalent in sub-Saharan Africa (Brun et al., 2010). In humans, the disease is caused by two sub-species of the protozoan Trypanosoma brucei while the African animal trypanosomiasis is caused by $T$. congolense, $T$. vivax, $T$. simia, $T$. evansi and T. b. brucei (Brun et al., 2010). Protozoan disease is responsible for significant morbidity and mortality worldwide. An estimated 60 million people are at risk of African trypanosomiasis infection with approximately 300,000 new cases every year (WHO, 1998). The most widely accepted method of managing the disease involved the use of trypanocidal drugs. The few available drugs, however, are faced with problems ranging from high cost, toxicity to prolonged duration of administration (Onyekwelu, 1999). The common, unregulated and underdosed use of the few drugs against the trypanosomes by quacks has resulted in increased parasite resistance (Afewerk et al., 2000), which maintains its resistance after cyclical tsetse transmission (Gray and Robert, 1971). Moreso, for most pharmaceutical companies, the high cost of developing new drugs, with little prospect of a fair financial return on their research and development investment, is a significant disincentive. Plants have always been a common source of orthodox drugs. In Africa, traditional medicine has a strong position in medical and veterinary care in the form of herbal therapy (Felerman, 2001).

Sterculia setigera, Del (synonyms- $S$. tomentose, Guill and Perr), is a savanna tree wide spread in tropical Africa. The plant $S$. setigera has been used in traditional medical practice by various communities in Africa (Tor-Anyiin et al 2011). The anti-viral activity of $S$. setigera against three human and three animal viruses (Poliovirus (type 1), astrovirus, human herpes simplex virus (type 1), equine herpes simplex virus, bovine parvovirus and canine parvovirus have also been reported (Caleb and Myint 2000). Several studies 
BAJOPAS Volume 14 Number 1, June, 2021

have provided supporting evidence of the use of this plant as an antimicrobial and antiinflammatory in folk medicine (Babalola et al., 2012).

Nevertheless, nanomedicine via nanocarrier and nano-delivery systems are rapidly developing sciences where materials in the nanoscale range are employed to serve as means of diagnostic tools or to deliver therapeutic agents to specific targeted sites in a controlled manner (Jayanta et al., 2018).Gold nanoparticles (AuNPs) are particularly preferable because of their favorable properties such as non-toxicity, ease of functionalization via ligand exchange, which enhances the capability of binding with drug molecules and simple fabrication in various sizes and shapes. Hence, AuNPs, owing to their small size, can be good candidates as drug carriers (Kimling et al., 2006). The high cost of trypanocides, their unavailability in remote areas, and, in particular, resistance (Afewerk et al.2000) and their serious side effects have all led the pendulum of medical treatment to swing back to the side of traditional medicine in recent years. The importance and value of traditional and indigenous herbal medicine was the subject of a campaign of the World Health Organization (WHO).

The purpose of this research was therefore to determine the efficacy of the trypanocidal activities of Sterculiasetigera crude and it's AuNPs-nano-conjugate against $T$. brucei brucei infection in mice.

\section{Experimental}

Materials

The chemicals used in this study include polyethylene glycol (Molecular Weight $=2000$ ), $1 \mathrm{mM}$ Hydrogen tetra auric acid $\left(\mathrm{HAuCl}_{4}\right)$ and ethanol. The parasite (Trypanosoma brucei brucel) used was Federe strain obtained from the Nigeria Institute for Trypanosomiasis Research (NITR) Kaduna, Kaduna State, Nigeria. Healthy albino mice of weighing between $25-27 \mathrm{~g}$ were purchased from Ahmadu Bello University Zaria. They were fed with rat pellets and were allowed to tap water ad libitum throughout the study period. The experiments were conducted in strict compliance with internationally accepted principles for laboratory animals' use and care as contained in the Canadian Council on Animal Care Guidelines and Protocol Review (Ernest et al., 1993) as approved by the departmental committee on postgraduate studies of the Federal University of Technology, Minna.

Collection and Identification of the Plant Material
The Stembark of Sterculia setigera was harvested from Gidan-kwano area of Federal University of Technology, Minna, Niger state, Nigeria. It was identified and authenticated in the Department of Plant Biology, Federal University of Technology, Minna, Nigeria with a voucher number, FUT/PLB/STER/001.

\section{Preparation and Extraction of plant sample}

Fresh stem of $S$. setigera together with the barkwas washed with distilled water, and then air dried at room temperature $\left(25 \pm 3^{\circ} \mathrm{C}\right)$ for fourteen days at the research laboratory of the Department of Biochemistry, Federal University of Technology Minna, Niger State. The plant material was milled to coarse powder using a mortar and pestle, and then kept in refrigerator $\left(-4^{\circ} \mathrm{C}\right)$. Powdered $S$. setigera $(30 \mathrm{~g})$ was extracted by reflux for 2 hours with $300 \mathrm{ml}$ each of ethanol and deionized water respectively. These extracts produced ethanol (ES) dried by heating in a water bath set at $40^{\circ} \mathrm{C}$ for 24 hours while the aqueous (AS) extract was dried using steam bath and percentage yield was then calculated. The dried extracts were finally stored in the refrigerator until required.

Phytochemical Screening of the Extracts

The qualitative phytochemical screening of the plant extracts was carried out as described in the methods of Sofowora (1993)to confirm the presence of alkaloids, saponins, tannins, steroids, flavonoids, terpenes, phenols and cardiac glycosides

Synthesis of Gold Nanoparticle

Fresh stem bark of Sterculia setigera was washed with running tap water and rinsed with distilled water and then air dried at room temperature. The dried bark was then reduced into coarse form using mortar and pestle. Five grams $(5 \mathrm{~g})$ of powdered $S$. setigera stem bark extract was transferred into $100 \mathrm{ml}$ of sterile deionized water Erlenmeyer flask.The solution was heated and allowed to boil for 3 minutes. It was cooled and filterered using whatman filter paper. The qualitative phytochemical analysis was carried out on the plant extract according to the methods of Sofowora (1993) to confirm the presence of alkaloids, saponin, flavonoids, cardiac glycosides, tannins, steroids, phlobatannin, terpenoids and anthraquinones. Then $0.5 \mathrm{ml}$ of filtrate was added to $9.5 \mathrm{ml}$ of aqueous 1 $\mathrm{mMHAuCl}_{4}$ solution for the reduction of $\mathrm{Au}^{3+}$ according tothe method described by Sivaraman et al.(2009). Colour change was observed and UV-Vis spectrophotometer was used to determine the wavelength. 
BAJOPAS Volume 14 Number 1, June, 2021 Characterization of Synthesized Gold Nanoparticle

The Ultraviolet-Visible spectrophotometry measurement of the synthesized gold nanoparticle was carried out using a UV 1800 Shimadzu spectrophotometer. The various peaks present in the mixture were measured over a range 190-800 nm. Dynamic Light Scattering (DLS) Malvern Zetasizer was used to measure the hydrodynamic particle size and distribution while High Resolution Transmission Electron Microscope (HRTEM, JEOL 1200EX) measured the morphological structure, shape and purity of particle produced (Shittu et al., 2017). The HRTEM analysis comes along with Energy Dispersive X-ray Spectroscopy (EDS) and Selected Area Electron Diffraction to determine the elemental composition and crystallinity of the sample respectively. Raman spectroscopy analysis was utilized to investigate the attached functional groups in the sample.

Functionalization of Gold Nanoparticles (AuNPs) The conjugation was carried out using synthesized $S$. setigera gold nanoparticle and powdered $S$. setigera extract to form nanoSterculia setigera conjugate. The conjugate was functionalized using polyethylene glycol (Molecular Weight $=2000$ ).

The functionalization of the AuNPs was carried out using a standarddrug (Diminazene aceturate) and polyethylene glycol (PEG). Different formulations were formed from three individual components to form three different composites. The first formulation (composite of PEG, gold nanoparticles and the extract) was prepared by adding $0.5 \mathrm{ml}$ of synthesized gold nanoparticle with $0.2 \mathrm{~g}$ of powdered $S$. setigera stem bark extract and properly stirred. Polyethylene glycol (2g) was then added and the resulting mixture was stirred for 1 hour using magnetic stirrer, and denoted as PNS. Second formulation (composite of polyethylene glycol and gold nanoparticles (PN) was obtained using $0.2 \mathrm{~g}$ of powdered $S$. setigera stem bark extract added to $0.5 \mathrm{ml}$ sterile deionized water. Two grams ( $2 \mathrm{~g})$ of PEG was also added to the mixture with proper stirring for 1 hour and this was denoted as PS. The third formulation (composite of PEG and the plant nanoparticle) was obtained by adding 0.5 $\mathrm{ml}$ of synthesized $S$. Setigera gold nanoparticle was added to $2 \mathrm{~g} \mathrm{PEG}$, and then stirred for 1 hour. The resulting mixture was denoted as PN. All the formulations were compounded into tablet form and left for 24 hrs in an incubator set at $37^{\circ} \mathrm{C}$ to enable wet digestion of the mixture, and then properly air dried.

Similar procedures for the 3 formulations were also carried out replacing plant extract with the standard trypanocidal drug, diminazene aceturate at $0.0035 \mathrm{~g}$.

\section{Concentration of the Drug Release}

Three test tubes containing $3 \mathrm{ml}$ of sterile deionized water were set up for each of the formulations above. The tablets were separately dissolved in each testube in a sterile environment for 3, 6 and 9 minutes. The height of each tablet and its diameter were first measured and then placed in a $3 \mathrm{ml}$ of sterile deionized water for $3 \mathrm{~min}$, then removed and the height and diameter were measured. The process was repeated at various time intervals until the whole tablet dissolved. The standard concentration of the drug and the absorbance of the various formulations were measured using the UV - Visible spectrophotometer (Shittu et al.2017).

\section{Inoculations of Laboratory Animals}

Blood from heavily infected donor mouse was obtained by cardiac puncture and collected with EDTA coated syringe to avoid clotting. The blood was immediately diluted with physiological saline $(\mathrm{pH} 7.4)$ to give $1.0 \times 10^{7}$ parasites per $\mathrm{ml}$ to serve as inoculum. Healthy mice for testing all the extract and nanoconjugates were then infected intraperitoneally with $0.1 \mathrm{ml}$ of the inoculum containing $10^{6}$ trypanosomes $/ \mathrm{ml}$.

Screening for Antitrypanosomal Activities of Extracts

The extracts were screened forantitrypanosomal activity using sixteen (16) mice grouped into A $D$ of four (4) animals each. All Animals were infected with $0.1 \mathrm{ml}$ containing $1 \times 10^{6}$ parasites.

Mice in groups $A$ and $B$ were untreated and Berenil treated at $3.5 \mathrm{mg} / \mathrm{kg}$ respectively while groups $C$ and $D$ mice were treated orally with ethanol and aqueous extracts at $200 \mathrm{mg} / \mathrm{kgbw}$ for 12 consecutive days respectively. The details of animal grouping are as shown below:

Group A: infected and untreated (negative control) (INT),

Group B: infected treated with standard drug (positive control) (ITD),

Group C: infected treated with Sterculiasetigera ethanol extract (ITES),

Group D: infected treated with Sterculiasetigera aqueous extract (ITAS)

Screening for Antitrypanosomal Activities of the Nanoconjugates 
BAJOPAS Volume 14 Number 1, June, 2021

This involved using a total of thirty-six (36) mice grouped E-M comprising of four animals per group. All the mice were infected with $0.1 \mathrm{ml}$ of infected blood containing $1 \times 10^{6}$ parasites and treatment with $S$. satigera conjugated nanoextract and diminazene aceturate were also by oral administration of $0.2 \mathrm{ml}$ each of the drug released at 3,6 and 9 minutes for 12 consecutive days. The detail of animal grouping was shown below:

Group E: infected, treated with $S$. setigera gold nanoparticle plus PEG" (PN, negative control)

Group F: infected treated with free Diminazine aceturate (ITFPD)

Group G: infected treated with free $S$. setigera extract (ITFPS)

Group $\mathrm{H}$ : infected treated with 3 minutes release

$S$. setigera conjugated nano-extract (IT3PNS)

Group I: infected treated with 6 minutes release S. setigera conjugated nano-extract (IT6PNS)

Group J: infected treated with 9 minutes release

S. setigera conjugated nano-extract (IT9PNS)

Group K: infected treated with 3 minutes release

Diminazine aceturate conjugate (IT3PND)

Group L: infected treated with 6 minutes release Diminazine aceturate conjugate (IT6PND)

Group M: infected treated with 9 minutes release Diminazine aceturate conjugate (IT9PND).
Monitoring the Activities of the Extracts

A drop blood samples collected from the tail end prick of each mouse were examined for the parasitemia at 2 days interval using the microscope (Herbert and Lumsden, 1976). The Packed Cell Volume (PCV) was determined at the commencement of treatment, and after 12 days post-treatment using the haematocrit centrifuge. The anti-trypanosomal effect of the extracts was assesed by comparing the level of parasitaemia (expressed as log of absolute number of parasites per milliliter of blood) in the treated animals with that of the control animals. Data Analysis

All data obtained in this work were statistically analyzed using analysis of variance (ANOVA) and Students T - test. Data obtained were subjected to a one-way analysis of variance to derive mean values of parasitemia among the treated groups and were considered to be significantly different if the level of probability was $<0.05$.

\section{RESULTS}

Percentage Yield and Phytochemical Compositions of the Extracts

The percentage yield after the ethanol and aqueous extraction was $10.15 \%$ and $31.91 \%$ respectively. The aqueous extract of the plant, $S$. setigera showed a higher yield than ethanol extract. The phytochemicals present in the plant extracts are presented in Table 1 below.

Table 1: Phytochemical Composition of S. setigeraStemback Extract

\begin{tabular}{l|cc}
\hline Phytochemicals & $\begin{array}{l}\text { Inference } \\
\text { Aqueous }\end{array}$ & Ethanol \\
\hline Tannins & + & + \\
Flavonoids & + & + \\
Saponins & + & + \\
Alkaloids & + & + \\
Cardiac glycosides & + & + \\
Steroids & - & - \\
Phenol & - & - \\
Terpenes & - & -
\end{tabular}

Keys: (+) present, (-) absent.

Antitrypanosomal Activity of S. setigera crude extracts

It was observed that there was appearance of parasite in the blood stream of the infected animals after forty-eight hours (2 days) of infection. The ethanol extract of Sterculia setigera (ITES) treated group recorded reduced parasitaemia when compared with the infected not treated group (INT). The aqueous treated group (ITAS) recorded steady increase in parasitaemia (Figure 1). 
BAJOPAS Volume 14 Number 1, June, 2021

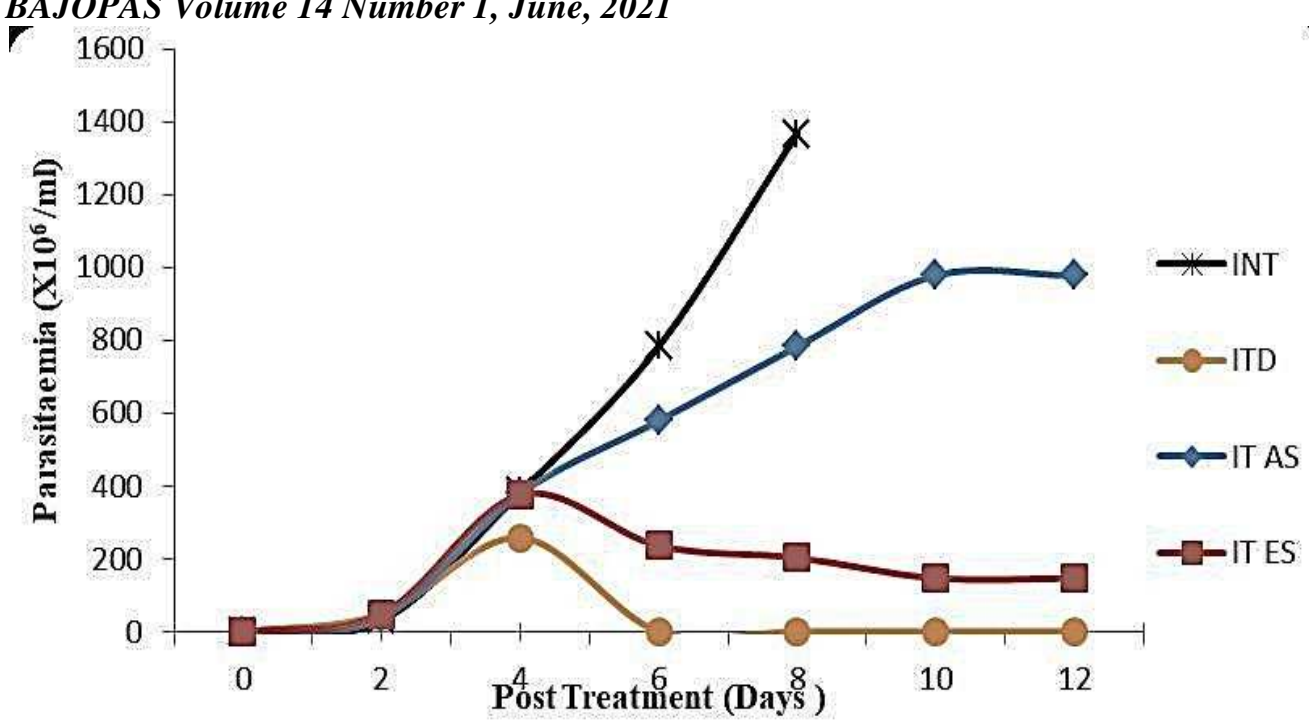

Figure 1:Parasitaemia $\left(x 10^{6} / \mathrm{ml}\right)$ of infected Mice and Treated with Sterculia setigeraEthanol and Aqueous Extracts

Key

IT AS: Infected treated with aqueous extract of Sterculia setigera

IT ES: Infected treated with ethanol extract of Sterculia setigera

INT: Infected not treated (Negative control)

ITD: Infected treated with standard drug (positive control)

Synthesis of Gold Nanoparticles

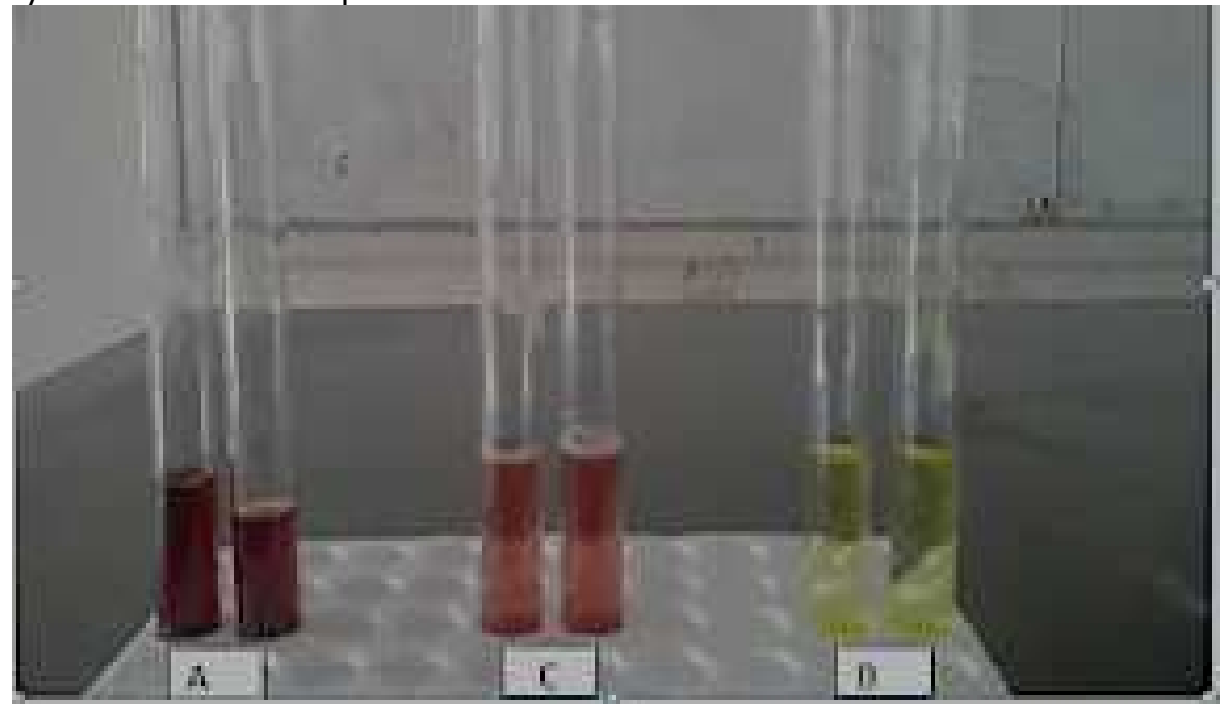

Figure 2: Changes in colour in the synthesis of Gold Nanoparticles

The Figure 2shows the colour change observed during the synthesis of gold nanoparticles.The (A) showed the aqueous stem bark extract of Sterculia setigera which was slightly red in colour, (B) was the gold chloride solution yellow in colour before reaction, and $(\mathrm{C})$ was the reddish colloidal dispersion formed within three minutes after the reaction of the aqueous stem bark extract of $S$. setigera and the gold chloride were combined resulting in the formation of gold nanoparticles.

Ultraviolet-visible (UV-vis) spectrophotometer of biosynthesized gold nanoparticle using Sterculia setigera aqueous stem bark extract The UV-vis spectra showed an absorption peak at $531.00 \mathrm{~nm}$, which is due to the surface plasmon resonance for the formation of gold nanoparticle (Figure 3) 
BAJOPAS Volume 14 Number 1, June, 2021

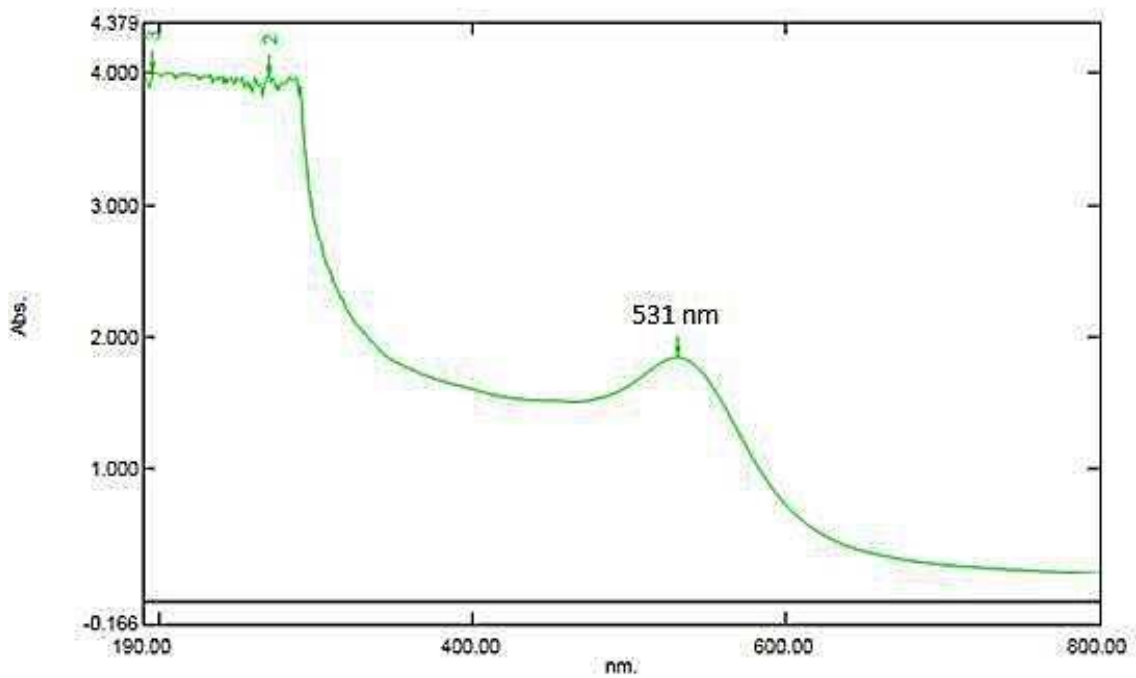

Figure 3: Absorption Spectra of Biosythesized Gold Nanoparticle Hydrodynamic particle size by Dynamic Light Scattering of gold nanoparticle using aqueous stem bark of Sterculia setigera

\section{Size Distribution by Intensity}

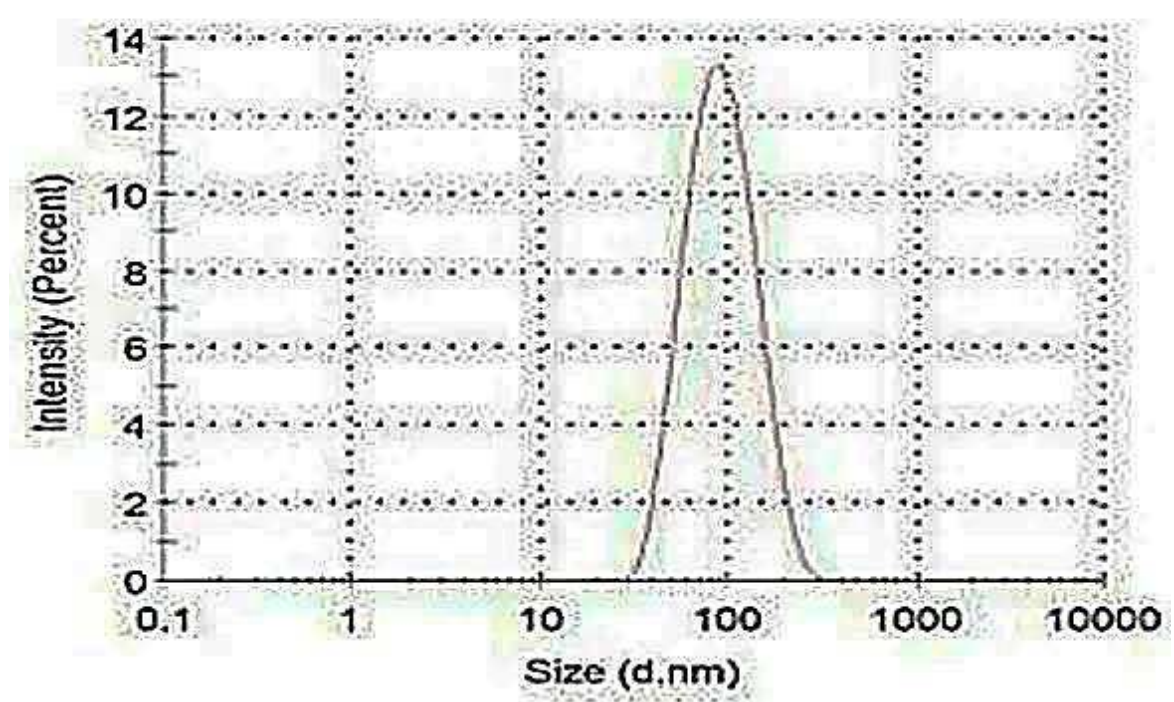

Figure 4: Particle size of gold nanoparticle using aqueous stem bark of Sterculia setigera

The average particle size of biosynthesized gold nanoparticles was $82 \mathrm{~nm}$ with intensity of $13 \%$. Morphology of biosynthesized gold nanoparticles The HRTEM monograph of biosynthesized and functionalized nanoparticle is shown in Figure 5 . The image revealed the shape to be spherical.

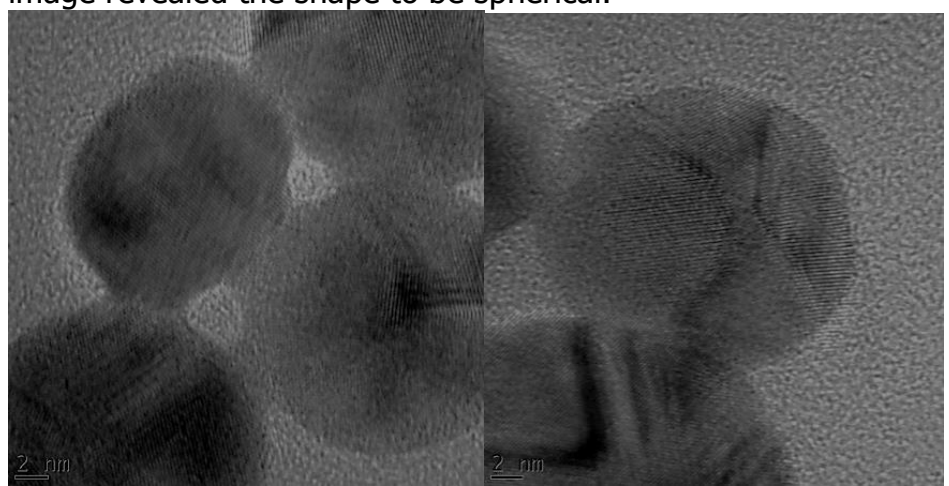

Figure 5: HRTEM of the Biosynthesized AuNPs

Energy Dispersive X-ray Spectroscopy (EDS) results of the biosynthesized gold nanoparticles. 
BAJOPAS Volume 14 Number 1, June, 2021

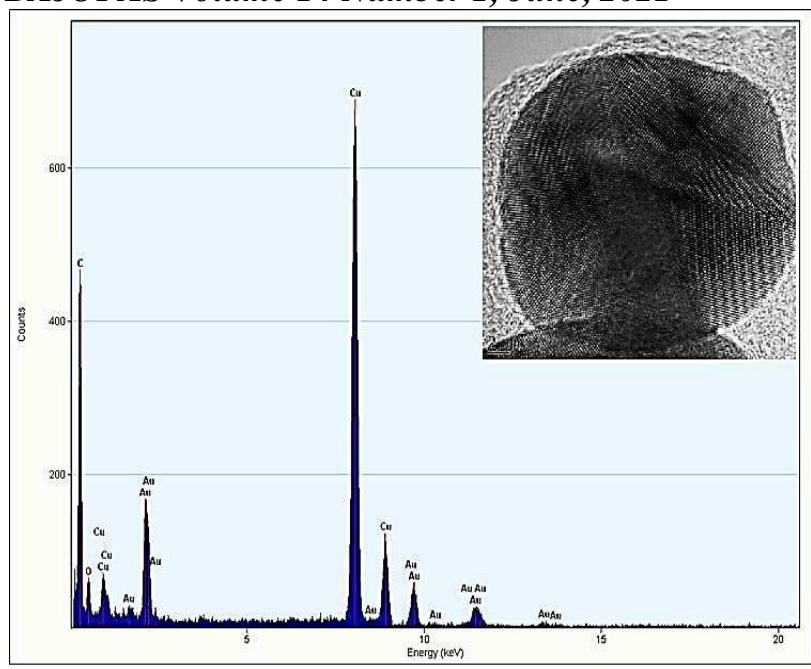

Figure 6:EDS spectrum of the Biosynthesized AuNPs (Inset: TEM image of a $20 \mathrm{~nm}$-sized gold particle)

Selected Area Electron Diffraction (SAED) patterns

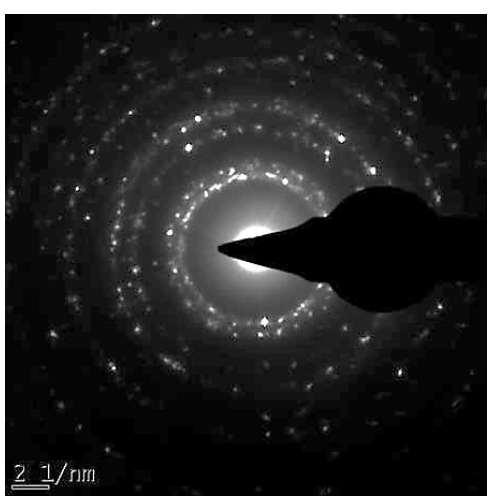

Figure 7:Selected Area Electron Diffraction (SAED) patterns of Biosynthesized AuNPs Raman spectrum of colloidal biosynthesized AuNPS

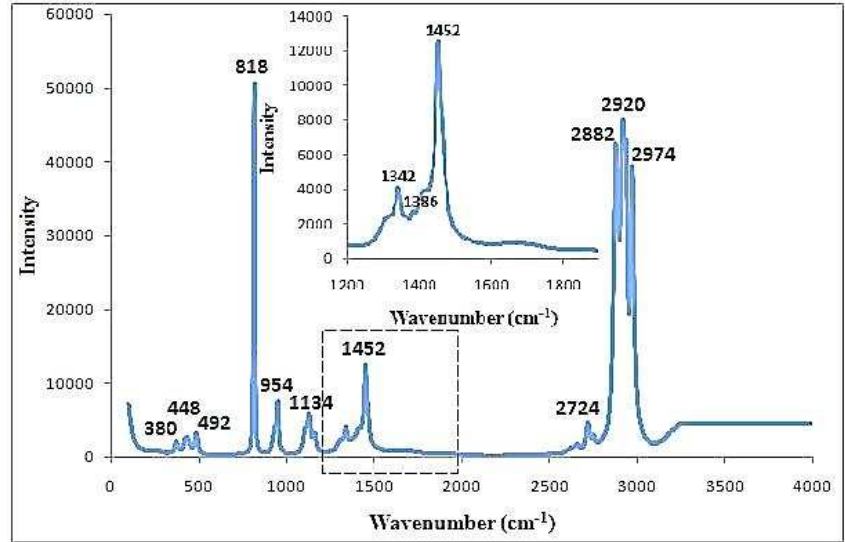

Figure 8:Raman spectrum of the Biosynthesized AuNPs. Inset: enlarged spectrum showing carboxylate stretching modes.

Drug Release for Nano-conjugated Sterculia setigera Extract and Diminazine Aceturate

The concentration of $S$. setigera extract released by PS $(5 \mathrm{mg} / \mathrm{ml})$ was significantly higher than that of Diminazine aceturate released by PD $(0.02 \mathrm{mg} / \mathrm{ml})$, at zero minutes. The nanoconjugated S.setigera (PNS) recorded higher releasing efficacy $(p>0.05)$ than that of nanoconjugated Diminazine aceturate (PND). At 9 minutes, PNS (9PNS) released $48.00 \mathrm{mg} / \mathrm{ml}$ amount of extract while PND (9PND) released $30 \mathrm{mg} / \mathrm{ml}$ of Diminazine aceturate. The concentration of PNS, released at 3 and 6 minutes (3PNS and 6PNS) are 31 and $37 \mathrm{mg} / \mathrm{ml}$ while PND (3PND and 6PND) released concentrations of 0.05 and $0.12 \mathrm{mg} / \mathrm{ml}$ respectively (Figure 9 ). 


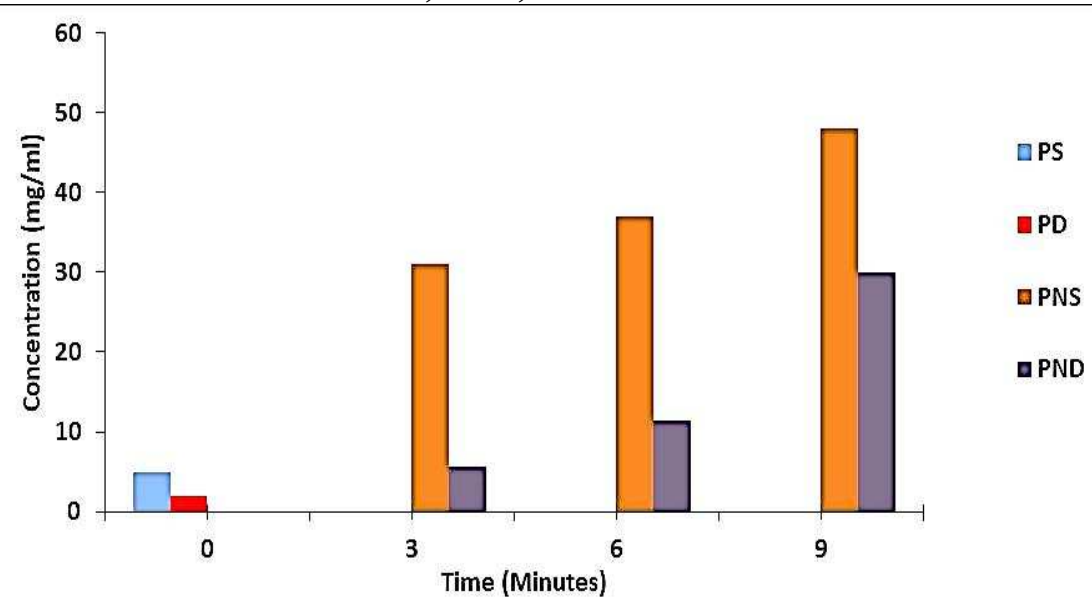

Figure 9: Release Capabilities of Nano-conjugated Sterculia setigera and Diminazine aceturate aceturate

Keys: PS: Free $S$. setigera, PD: Free Diminazine aceturate, PNS: nano-conjugated $S$. setigera extract, PND: nano-conjugated Diminazine aceturate

Antitrypanosomal Activities of Nano-conjugated Sterculia setigera Extracts at Different Release Time Nano-S. setigera-conjugations releasing time denoted as ITPNS (3PNS, 6PNS and 9PNS) resulted in the significant reduction of parasitaemia at various concentrations after day $6(p<0.05)$. The concentration released at 6 minutes (6PNS) releasing time gave the best activity leading to significant reduction $(p<0.05)$ in the parasitaemia between 4-10days with total clearance at twelve $(12)$ days post treatment of the infected mice. However, 3PNS, 9PNS and FPS also showed a decrease in parasitaemia from 6th day of treatment when compared with negative control but could not clear the parasite from the blood of the infected mice. In contrast, the parasitaemia of the negative control kept increasing indefinitely till death, while the positive control (ITFPD) Diminazine aceturate treated mice cleared the parasite at six (6) days post treatment (Figure 10).

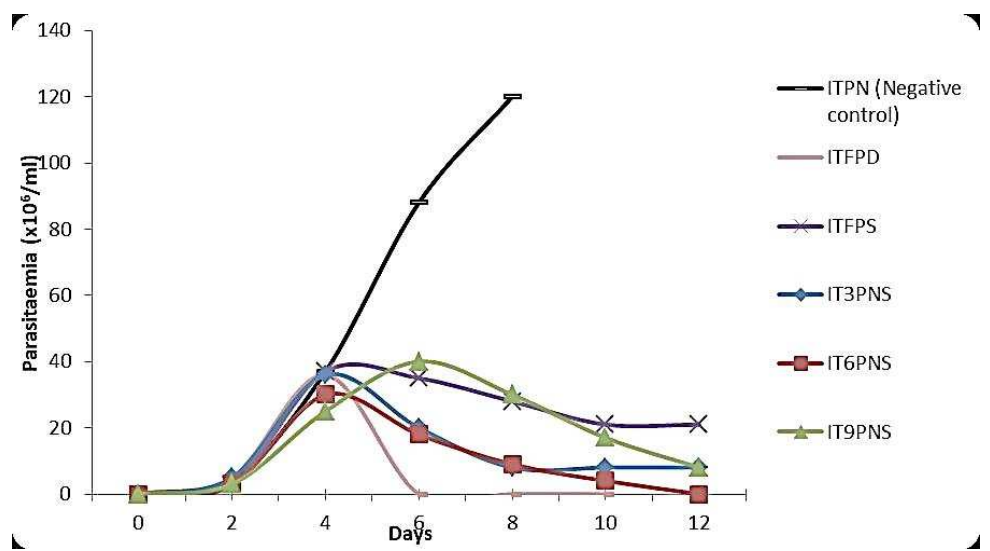

Figure 10:Parasitaemia of Mice Infected with T. brucei and Treated with Nano Conjugated $S$. setigera extract

Key: ITPN: infected treated with $S$. setigera gold nanoparticle and PEG (negative control), ITFPD: infected treated with free Diminazine acetutate extract, ITFPS infected treated with free $S$. setigera extract, IT3PNS: infected treated with $3 \mathrm{~min}$ release nano-conjugated $S$. setigera extract, IT6PNS: infected treated with 6 min release nano-conjugated $S$. setigera extract, and IT9PNS: infected treated with 9 min release nano-conjugated $S$. setigera extract

Antitrypanosomal Activities of Nano-conjugated Diminazine Aceturate at Different Release Time The concentrations of nano-conjugated Diminazine aceturate ITPND ( 3PND, 6PND and 9PND) at different releasing time have shown to significantly cleared the parasitaemia $(p<0.05)$.
They cleared the parasite completely from the blood of infected mice at 10th days post treatment when compared with the negative control group, which has its parasitaemia increasing steadily until the animal died of infection (Figure 11). 


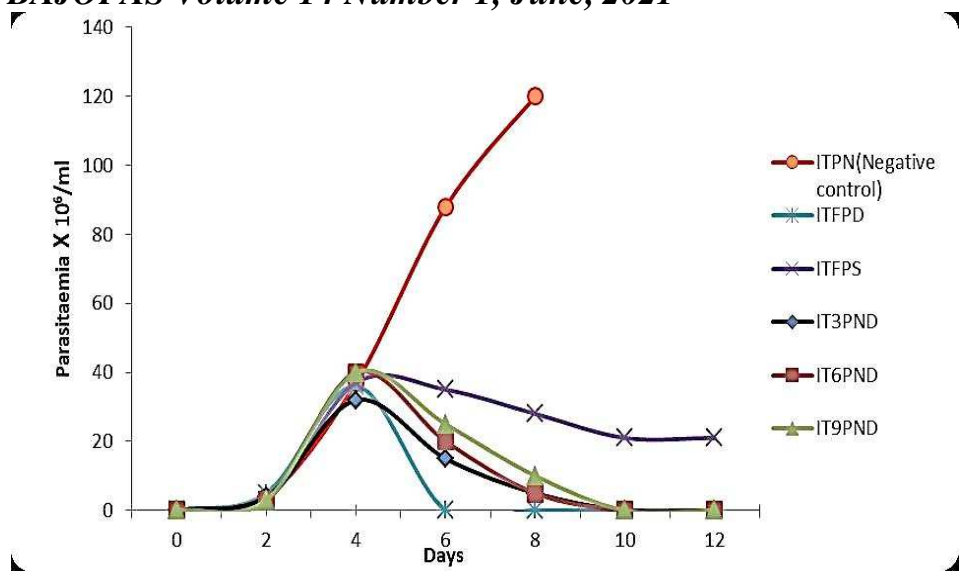

Figure 11:Parasitaemia of Mice Infected with T. brucei and Treated with Nano-Conjugated Diminazine Aceturate

Key: ITPN: infected treated with $S$. setigera gold nanoparticle and PEG (negative control), ITFPD: infected treated with free Diminazine acetutate, ITFPS infected treated with free $S$. setigera extract, IT3PND: infected treated with 3 min release nano-conjugated Diminazine aceturate, IT6PND: infected treated with 6 min release nano-conjugated Diminazine aceturate and IT9PND: infected treated with

| 9 min release nano-conjugated Diminazine aceturate

pretreatment (D0T), with the exception of IT3PNS animals which have its PCV reduced $(p<0.05)$ Changes in Packed Cell Volume of infected mice Treated with Ethanol Extract and Nano-Conjugated Diminazene Aceturate and S. setigera

The mean percentage Packed Cell Volume (PCV) of $T$. b. brucei infected mice treated with $S$. setigera ethanol crude extract is presented in Table 2. There was a general decrease in PCV of all the groups after establishment of infection and at pretreatment (PI). At day twelve post treatment (PT12), the PCV of animals in all the treated groups (ITAS, ITES and ITD) increased significantly $(p<0.05)$ when compared to pretreatment (PT0) and preinfection (PI) values. All animals in infected and untreated control (INT) died before twelve days of treatment.

Similarly, Table 3 shows the PCV of all the infected and treated at day twelve post treatment (D12T) increased significantly $(p<0.05)$ when compared to their values at

Table 2:Changes in PCV of T. brucei Infected Mice and Treated with $S$. setigera Extracts

\begin{tabular}{|c|c|c|}
\hline Preinfection (PI) & Pretreatment (PT0) & Post Treatment (PT12) \\
\hline 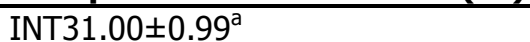 & $30.00 \pm 0.61^{\mathrm{a}}$ & $\mathrm{D}$ \\
\hline ITD28.00 $\pm 0.31^{\mathrm{b}}$ & $27.00 \pm 0.65^{\mathrm{b}}$ & $34.00 \pm 0.37^{\mathrm{a}}$ \\
\hline ITAS29.00 $\pm 0.52^{\mathrm{b}}$ & $28.00 \pm 0.80^{\mathrm{b}}$ & $34.00 \pm 0.48^{\mathrm{a}}$ \\
\hline ITES32.00 $\pm 0.98^{\mathrm{b}}$ & $30.00 \pm 0.92^{\mathrm{b}}$ & $44.00 \pm 0.78^{\mathrm{a}}$ \\
\hline
\end{tabular}

Key

INT: Infected not treated (Negative control) control

ITD: Infected treated with standard drug (positive)

IT AS: Infected treated with aqueous extract of $S$. setigera

IT ES: Infected treated with ethanol extract of $S$. setigera

$\mathrm{D}=$ Died

Different superscripts ${ }^{a}$ and ${ }^{b}$ along the same row are statistically significant at $p<0.05$ 
BAJOPAS Volume 14 Number 1, June, 2021

Table 3:Changes in PCV of T. brucei Infected Mice and Treated with Nano-Conjugated Diminazene Aceturate and $S$. setigera Extract at Different Releasing Time

\begin{tabular}{lccc}
\hline Groups & Preinfection(PI) & Pretreatment(PTO) & Post Treatment (PT12) \\
\hline ITPN & $52.00 \pm 0.82^{\mathrm{a}}$ & $48.00 \pm 0.87^{\mathrm{b}}$ & $\mathrm{D}$ \\
ITFPD & $57.00 \pm 0.81^{\mathrm{b}}$ & $56.00 \pm 0.73^{\mathrm{b}}$ & $61.00 \pm 0.61^{\mathrm{a}}$ \\
ITFPS & $48.00 \pm 0.61^{\mathrm{b}}$ & $44.00 \pm 0.86^{\mathrm{c}}$ & $55.00 \pm 0.79^{\mathrm{a}}$ \\
IT3PNS & $48.00 \pm 0.51^{\mathrm{a}}$ & $46.00 \pm 0.30^{\mathrm{a}}$ & $41.00 \pm 0.91^{\mathrm{b}}$ \\
& & & \\
IT6PNS & $58.00 \pm 0.70^{\mathrm{b}}$ & $59.00 \pm 0.19^{\mathrm{b}}$ & $60.00 \pm 0.81^{\mathrm{a}}$ \\
& & & \\
IT9PNS & $50.00 \pm 0.90^{\mathrm{b}}$ & $48.00 \pm 0.95^{\mathrm{b}}$ & $56.00 \pm 0.61^{\mathrm{a}}$ \\
& & & \\
IT3PND & $50.00 \pm 0.90^{\mathrm{b}}$ & $49.00 \pm 0.11^{\mathrm{b}}$ & $59.00 \pm 0.98^{\mathrm{a}}$ \\
IT6PND & $42.00 \pm 0.89^{\mathrm{b}}$ & $40.00 \pm 0.41^{\mathrm{b}}$ & $53.00 \pm 0.92^{\mathrm{a}}$ \\
IT9PND & $46.00 \pm 0.99^{\mathrm{b}}$ & $44.00 \pm 0.18^{\mathrm{b}}$ & $59.00 \pm 0.85^{\mathrm{a}}$ \\
\hline
\end{tabular}

Keys:

ITPN: infected treated with S. setigera gold nanoparticle and PEG (negative control)

ITFPD: infected treated with free Diminazine acetutate

ITFPS infected treated with free $S$. setigera ethanol extract

IT3PNS: infected treated with 3 min release nano-conjugated $S$. setigera extract

IT6PNS: infected treated with 6 min release nano-conjugated $S$. setigera extract

IT9PNS: infected treated with 9 min release nano-conjugated $S$. setigera extract

IT3PND: infected treated with 3 min release nano-conjugated Diminazine aceturate

IT6PND: infected treated with 6 min release nano-conjugated Diminazine aceturate

IT9PND: infected treated with 9 min release nano-conjugated Diminazine aceturate

D: Died

Different superscripts ${ }^{a}$ and ${ }^{b}$ along the same row are statistically significant at $p<0.05$

Changes in bodyweight (g) of T. b. brucei Infected Mice and Treated with Nano- Conjugated S. Setigera and Ethanol extract

In Table 4 , the animals in all the groups have their bodyweight decreased $(p>0.05)$ just before the commencement of the treatment (PT0), but the values later increased significantly $(p<0.05)$ at day twelve (12) post treatment (PT12) particularly mice in ITES group.

Similar observation was also recorded for the nano conjugated diminazene aceturate and $S$. setigera treated groups (Table 5). However, the bodyweight of animals in groups treated with IT6PNS and IT6PND increased significantly $(p<0.05)$ at day 12 post treatment $(P T 12)$ more than other treatment when compared to that at day zero of tratment (PT0).

Table 4:Bodyweight $(\mathrm{g})$ of $T$. brucei Infected Mice and Treated $S$. setigera Extract

\begin{tabular}{lcc}
\hline Groups $\quad$ Preinfection(PI) & Pretreatment(PT0) & Post Treatment (PT12) \\
\hline INT24.00 $\pm 0.41^{\mathrm{a}}$ & $22.00 \pm 0.83^{\mathrm{a}}$ & $\mathrm{D}$ \\
ITD 26.00 $0.86^{\mathrm{a}}$ & $24.00 \pm 0.31^{\mathrm{a}}$ & $27.00 \pm 0.99^{\mathrm{a}}$ \\
ITAS25.00 $\pm 0.18^{\mathrm{a}}$ & $24.00 \pm 0.52^{\mathrm{a}}$ & $25.00 \pm 0.79^{\mathrm{a}}$ \\
ITES26.00 $\pm 0.41^{\mathrm{b}}$ & $25.00 \pm 0.19^{\mathrm{b}}$ & $30.00 \pm 0.80^{\mathrm{a}}$ \\
\hline
\end{tabular}

keys

INT: Infected not treated (Negative control) control

ITD: Infected treated with Diminazine acetutate (positive)

IT AS: Infected treated with crude aqueous extract of $S$. setigera

IT ES: Infected treated with crude ethanol extract of $S$. setigera

$\mathrm{D}=$ Died

Different superscripts ${ }^{a}$ and ${ }^{b}$ along the same row are statistically significant at $p<0.05$ 
BAJOPAS Volume 14 Number 1, June, 2021

Table 5:Bodyweight $(\mathrm{g})$ of $T$. b. brucei Infected Mice Treated with Nano-Conjugated Diminazene Aceturate and $S$. setigera Extract.

\begin{tabular}{lccc}
\hline Groups & Preinoculation(PI) & Pretreatment(PT0) & Post Treatment (PT12) \\
\hline ITPN & $20.00 \pm 0.69^{\mathrm{a}}$ & $19.00 \pm 0.61^{\mathrm{a}}$ & $\mathrm{D}$ \\
ITFPD & $21.00 \pm 0.58^{\mathrm{a}}$ & $20.00 \pm 0.80^{\mathrm{a}}$ & $21.90 \pm 0.58^{\mathrm{a}}$ \\
ITFPS & $23.50 \pm 0.83^{\mathrm{a}}$ & $22.30 \pm 0.19^{\mathrm{a}}$ & $25.00 \pm 0.81^{\mathrm{a}}$ \\
IT3PNS & $19.00 \pm 0.48^{\mathrm{a}}$ & $17.30 \pm 0.70^{\mathrm{a}}$ & $16.50 \pm 0.81^{\mathrm{a}}$ \\
IT6PNS & $20.40 \pm 0.69^{\mathrm{b}}$ & $19.20 \pm 0.69^{\mathrm{b}}$ & $25.50 \pm 0.59^{\mathrm{a}}$ \\
IT9PNS & $20.00 \pm 0.69^{\mathrm{a}}$ & $19.80 \pm 0.81^{\mathrm{a}}$ & $16.00 \pm 0.98^{\mathrm{a}}$ \\
IT3PND & $24.80 \pm 0.80^{\mathrm{a}}$ & $21.50 \pm 0.98^{\mathrm{a}}$ & $26.20 \pm 0.17^{\mathrm{a}}$ \\
T6PND & $25.30 \pm 0.17^{\mathrm{a}}$ & $19.80 \pm 0.40^{\mathrm{b}}$ & $26.20 \pm 0.17^{\mathrm{a}}$ \\
IT9PND & $26.00 \pm 0.91^{\mathrm{b}}$ & $23.50 \pm 0.97^{\mathrm{ab}}$ & $22.20 \pm 0.29^{\mathrm{a}}$ \\
\hline
\end{tabular}

Different superscripts ${ }^{a}$ and ${ }^{b}$ along the same row are statistically significant at $p<0.05$

Keys

ITPN: infected treated with S. setigera gold nanoparticle and PEG (negative control)

ITFPD: infected treated with free Diminazine acetutate

ITFPS: infected treated with free $S$. setigera extract

IT3PNS: infected treated with 3 min release nano-conjugated $S$. setigera extract

IT6PNS: infected treated with 6 min release nano-conjugated S. setigera extract

IT9PNS: infected treated with 9 min release nano-conjugated $S$. setigera extract

IT3PND: infected treated with 3 min release nano-conjugated Diminazine aceturate

IT6PND: infected treated with 6 min release nano-conjugated Diminazine aceturate

IT9PND: infected treated with 9 min release nano-conjugated Diminazine aceturate

\section{DISCUSSION}

Biosynthesis of Gold Nanoparticles

The use of herbal medicine is another approach for the treatment of disease; however because of differences in composition, the biological effects on the parasite differ. Nanotechnology is a technology that enhances the use of gold nanoparticles (AuNP) in area of medical applications, especially as a drug carrier for targeted drug delivery. Thus, the use of nanoparticle to deliver the active component to the target cells has potential to alleviate the drawbacks of the conventional and herbal therapy.

This study revealed a variation in the percentage yield of the extracts when ethanol and aqueous solvents were used for their extraction. These variations might be due to the polarity of solvent used. The aqueous extracts have higher yield than that of the ethanol, suggesting a high proportion of water-soluble components. Water is a solvent with highest polarity and as such, all polar compounds will be removed by water, including those extracted by less polar solvents (Ogoti et al., 2009).

The qualitative phytochemical composition of the two extracts of Sterculia setigerais presented in Table 2, which indicates the presence of tannins, flavonoids, saponins, alkaloids, and cardiac glycoside whilesteroids phenols and terpenes were absent. The presence of tannins and flavonoids (Table 1) which are examples of polyphenolic compounds are of great importance in green synthesis of nanoparticles due to their reductive and antioxidant abilities. Tannins have been reported as reducing and stabilizing agents in the synthesis of silver nanoparticles (Raghunandan et al., 2010). The flavonoids present also were found to be responsible for reduction process to produce AuNPs (Raghunandan et al., 2010). The presence of alkaloids and saponins shows that the Sterculia setigeradoes contain compounds with basic nitrogen atoms and foaming characteristic which basically are reported to have trypanocidal effect (Ene et al., 2009).

The reduction in parasitaemia observed in the group treated with Sterculia setigera ethanol extract (Figure 1), may be due to secondary metabolites in the extract. Some secondary metabolites have previously reported to possess antitrypanocidal properties (Ene et al., 2009). Therefore, ethanol extract of Sterculia setigera was said to be trypanostatic since it has the ability to prolong the life of the treated groups beyond that of the infected untreated control group. However, trypanostatic effects are known to suppress the activity of the parasite thereby prolonging the life of the infected mice when compared to the untreated infected control. The aqueous extract of the stembark of $S$. setigera had no antitrypanosomal effect (Figure 1). The possible reason could be that the aqueous extract has several polar compounds extracted and could be masking the effect of the most active compound(s). 


\section{BAJOPAS Volume 14 Number 1, June, 2021}

The anti-trypanosomal activities of nanoconjugated Sterculia setigera extract (PNS), could be attributed to nanoparticle's ability to deliver the active component (Secondary metabolites) in the plant extract to the target site. Gold nanoparticles (AuNPs) have been reported as an excellent candidate for drug delivery vehicles due to their unique physical and chemical properties, enabling the transport and subsequent release of therapeutic payloads such as drugs or genetic materials to specific tissue sites (Ghosh, 2008). Also, the high surface area $(>900 \mathrm{~m} 2 / \mathrm{g})$ and large pore volume $(>0.9$ $\mathrm{cm} 3 / \mathrm{g}$ ) of gold nanoprticle have been reported to allow easy loadings of drug molecules (Slowing et al., 2008). Hence, the observation recorded agrees with Olbrichet al.(2002), who have shown that gold nanoparticle delivered Diminazine aceturate to target site. In this tudy, it was observed that 6PNS, which has the lower released concentration of extract as compared to 9PNS, had better activitites (Figure 9). In PNS, 9PNS has the highest releasing efficacy (48.00 $\mathrm{mg} / \mathrm{ml}$ ) but its biological activity was lower when compared with 6PNS $(37.00 \mathrm{mg} / \mathrm{ml})$. All PND show a progressive increase in concentration of Diminazine aceturate release, but have similar biological activity (Figure 10). This means that PND delivered activity at 3,6 , and 9 minutes to the target site while PNS (6PNS) only delivered completely at 6th minute, as compared to the PS and PD (free extract and diminazine aceturate). The anti-trypanocidal activity of PND and PNS (6PNS) confirms the use of metal nanoparticles as a carrier to target site.

Comparatively, Sterculia setigera stembark ethanol extract has lesser activity than its nanoconjugations. There was reduced parasitaemia which resulted into prolongation of life beyond that of control when ethanol extract of $S$. setigera was administered (Figure 3 ). However, the administration of Nanoconjugations of the same plant extract resulted to total clearance of parasites from blood circulation (Figure 10). Consequently, the ethanol extract was trypanostatic while its nanoconjugation was trypanocidal. The gold nanoparticle has increased the efficacy of the extracts by conveying and delivering the extracts to the target trypanosomal parasites. This result has indicated that, conjugating Sterculia setigera stem bark extracts with gold nanoparticle minimizes the extracts instability, deliver extract to target sites and thereby increasing its therapeutics effects. Nanocarriers as applied to herbal remedies will deliver optimum amount of the drug to their site of action, bypassing all the barriers such as acidic $\mathrm{pH}$ of stomach, liver metabolism and increase the prolonged circulation of the drug into the blood due to their small size (Kuntal et al., 2005). Also, Wang et al.(2010) had demonstrated that nanoparticle improved performance of drugs in both stability and hydrophilicity.

Characterization of the Biosynthesized Gold Nanoparticles

A characteristic absorbance peak at $531 \mathrm{~nm}$ further confirms the presence of gold nanoparticles in the final suspension (Figure 3 ). Generally, gold nanoparticle displays a single absorption peak in visible range between 500 $550 \mathrm{~nm}$ (Ghosh, 2008) as seen in Figure 4. Absence of other peaks above $550 \mathrm{~nm}$ indicates the mono-dispersity of the particles. This can be attributed to the excitation of Surface Plasmon Resonance (SPR) vibration in the AuNPs due to its special shape and structure which often exhibit distinctive SPR peaks in the UV-visible region which was coincident with the plasmon band of spherical gold nanoparticles. Similar results were reported earlier by Aromal et al.(2012); Kumar et al.(2012) and Shenyet al.(2011).

The size distribution (hydrodynamic radius) of the biosynthesized AuNPs in suspension was measured using Nano-zetasizer DLS. Results obtained as presented in Figure 5 indicate that the hydrodynamic average size in diameter of the AuNPs synthesized is in the range $44-144$ $\mathrm{nm}$ (hydrodynamic size range peculiar to spherical shape of gold nanoparticles). The HRTEM analysis depicts the morphology in terms of shape, purity and size of colloidal nanoparticles. The size and shape of gold nanoparticles strongly influence their properties and this might have contributed to the antitrypanocidal activities of AuNPS-nanoSterculia setigera conjugate. Spherical shape of gold nanoparticle was observed in Figure 5 with particle size of approximately $20 \mathrm{~nm}$ (Figure 6) and has been reported to have antibacterial activities against both Gram positive and Gram negative bacteria (Smitha and Gopchandran, 2013). This shape was consistent with the work by Huang et al. (2001) that synthesized spherical shaped as well as triangular gold nanoparticles of $80 \mathrm{~nm}$ in size using sun-dried biomass of Cinnamomum camphora leaf.

The elemental analysis of the biosynthesized AuNPs was performed using the EDS and the result obtained is presented in Figure 6. Results as presented clearly indicate that particle produced was AuNPs. The peaks situated at bonding energies of approximately 1.1, 8.1 and $9 \mathrm{keV}$ belong to copper while the first peak belong to carbon (both represent TEM holding grids). On the other hand, the elemental carbon could also be from the carboxyl group in the 
BAJOPAS Volume 14 Number 1, June, 2021 synthesized colloid. It can be deduced from the TEM/EDS results that the biosynthesized gold nanoparticles have high purity. The SAED patterns of the biosynthesized AuNPs in Figure 8 showed that the samples are polynanocrystalline having narrow particle size distributions accompanied with multiple rings (ring represents diffraction from specific crystal groups of similar size). The rings are indicative of different phases present in the gold nanoparticles. Also, there are several bright spots which are consequence of reflections from few individual crystals.

Raman spectroscopy is an effective means of evaluating the quality and chemical compositions of nanoparticles (Afolabi et al., 2011). The Raman spectra of the biosynthesized AuNPs as presented in Figures 8 indicate different peaks at different wavenumber in the ranges of $500 \mathrm{~cm}^{-1}$ to $3000 \mathrm{~cm}^{-1}$. The $\mathrm{OH}$ stretching mode is absent in the Raman spectra indicating that phenol present in the reducing agent (plant extract) was reactive to form other functionality within the new product (AuNPs). Again, the stretching modes of the carboxylates between 1300 and $1600 \mathrm{~cm}^{-1}$ are evidence of certain molecular interactions in the biosynthesized AuNPs.

\section{Effect of Biosynthesized Gold nanoparticles}

The observed trypanostatic effect of the Sterculia setigera ethanolic extract (ES) was accompanied by corresponding increase in PCV (Table 2). The increase in packed cell volume observed in ITES and ITAS (Infected treated with aqueous extract of Sterculia setigera) is in conformity with the work of Musaet al. (2011) who had previously reported that Sterculia setigera have hematopoietic-stimulating factor. Similarly, animals in groups 6PNS, 9PNS, 3PND, 6PND and 9PND treated groups suffered less anaemia as compared with the negative control group (Tables 2 and 3 ). This can be substantiated with the reports of Hauck et al.(2010) where $80 \mathrm{~nm}$ gold nanoparticle

\section{REFERENCES}

Abubakar, A., Iliyasu, B., Ojiegbu, F.N., Igweh, A.C., Shamaki, B.U., Dung, E.C., Domtur, L.L., Okogun J.O., Gbodi, T. A., and Ogbadoyi, E.O. (2011). Evaluation of the antitrypanosomal activity of Cucumis metuliferus pulp extract in Rabbits. Journal of Medicinal Plant Research. 5(11), 2136-2142.

Afewerk, Y., Clansen, P. H., Abebe G., Tilahun, G. and Mehlitz, D., (2000). Multiple-drug Resistant Trypanosoma congolense populations in village cattle of Metekel district, northwest Ethiopia. Acta Tropical; 76: $231-238$. increased red blood cell production and packed cell volume in mice. The decrease packed cell volums observed in animals treated with 3PNS could be due to low concentration of Sterculia setigera in the conjugation. Anaemia is the most outstanding clinical and laboratory feature of African trypanosomiasis (Suliman and Fieldman, 1989) and also the primary cause of death (Losos and Ikede, 1972). Anemia as indicated by low PCV level is known to worsen with increasing parasitaemia (Suliman and Fieldman, 1989). The prolongation of lives of treated animals may therefore also be associated with the ability of this extract to improve the PCV possibly by reducing the parasite replication and toxin release.

Furthermore, the result for the bodyweight of animals (Tables 4 and 5) which increased in all the treated animals indicates that the animals in ITAS and ITES and nanoconjugated and diminazene aceturate groups were in a better physical state to eat more than those in the other groups. They were therefore more able to resist weight loss that is usually associated with trypanosomiasis. The weight lost observed in ITAP, ITEP and INT groups is similar with the report of Abubakar et al. (2011) in which infection with $T$. brucei was associated with weight loss in mice and rats.

\section{CONCLUSION}

The study has provided evidence that crude ethanol extract of Sterculia setigera prolonged the life span of $T$. brucei infected animals while its Nano-conjugation resulted to the total clearance of the parasite from the blood circulation. There was also improvement in PCV and weight loss associated with experimental trypanosomiasis. Consequently, Sterculia setigera as herbal medicine and its nanoconjugate has potential in the management of Africa Trypanosomiasis.

Afolabi, A. S., Abdulkareem, A. S., Mhlanga, S. D. and Iyuke, S. E. (2011). Synthesis and purification of bimetallic catalysed carbon nanotubes in a horizontal CVD reactor", Journal of Experimental Nanoscience, 6(3): 248-262.

Aromal, S.A., Vidhu, V.K. and Philip, D. (2012) Green synthesis of well dispersed gold nanoparticles using Macrotyloma uniflorum. Spectrochim. Acta, Part A 85, 99-104

Babalola, I.T., Adelakun, E. A., Wang V. and F.O. Shode. (2012). Anti-TB Activity of Sterculia setigera Del. leaves (Sterculiaceae). Journal of 
BAJOPAS Volume 14 Number 1, June, 2021 Pharmacognosy and Phytochemistry 1(3):17-23.

Brun, R., Blum, J., Chappuis, F. and Burri, C. (2010). Human African Trypanosomiasis. Lancet 375:148-159.

Caleb, A.K. andMyint, S.H (2000). Antiviral activity of some Nigerian medicinal plant extracts. Journal of Ethnopharmacology 68(1-3): 289-94. DOI: $10.1016 / \mathrm{S0378-}$ 8741(99)00049-5

Ene, A. C., Edeh, N. G., Bonny-Okoli, C., Ojiako, O. A., Ujowundu, C. O. and Igwe, C. U. (2009). In vitro and in vivo Antitrypanosomal Effects of Methanol and Aqueous Extracts of Picralima nitida. British Journal of Pharmaceutical Research4(5): 644-653.

Ernest, D., Olfert, D.V., Brenda, M., Cross, V.M. and McWilliam, A. A. (1993). Guide to Care and Use of Experimental Animals. 2nd edition, Canadian Council on Animal Care.

Felerman, E. K. (2001). Alternative Medical Services in Rural Tanzania: a physician's view. Society and Science of Medicine. 158: 399-404.

Ghosh, P. (2008). Gold nanoparticles in delivery applications. Advance Drug Delivery Review. 60: (11):1307-1315.

Gray, A.R. and Roberts, C.J. (1971). The cyclical transmission of strains of Trypanosoma congolense and $T$. vivax resistant to normal therapeutic doses of trypanocidal drugs. Parasitology, 63: 67-89.

Hauck, T. S., Anderson, R. F., Fischer, H. C., Newbigging, S. and Chen, W. (2010). In vivo gold nanoparticle in mince toxicity assessment. Small; 6: 138-144.

Herbert, W.J, and Lumsden, W. H. R. (1976) Trypanosoma brucei: A rapid matching method for estimating the host parasitaemia. Exp. Parasitol 40: 427431.

Huang, M. H., Mao, S., Feick, H., Yan, H., Wu, Y., Kind, H., Weber, E., Russo, R. and Yang, P. (2001). Room -Temperature Ultraviolet Nanowire Nanolasers. Science. 292: 1897-1899.

Jayanta, K. P., Gitishree, D., Leonardo, F. F., Estefania, V. R. C., Maria del Pilar, R., Laura, S. A., Luis, A., Renato, G., Mallappa, K. S., Shivesh, S., Solomon, H. and Han-Seung, S. (2018). Nano based drug delivery systems: recent developments and future prospects. Journal of Nanobiotechnology. 6:7 1https://doi.org/10.1186/s12951018-0392-8, 1-33.
Kimling. J.M, Maier.,O.V Kotaidis,H., Ballot,A.,\& Piech (2006) Turkevich Method for Gold Nanoparticle Synthesis Revisited" Journal of Physical Chemistry (110) 15700-15707.

Kuntal, M., Mukherjee, K. and Ahamed, H. (2005). Enhanced therapeutic benefit of Quercitin- phospholipid complex in carbon tetrachloride induced acute liver injury in rats: A comparative study. Iran Journal of Pharmacology and Therapeutics. 4: 84-90.

Kumar, K.M., Mandal, B.K., Sinha, M., Krishnakumar, V. (2012). Terminalia chebula mediated green and rapid synthesis of gold nanoparticles. Spectrochimica Acta, Part A, 86 490-494

Losos, G. J. and Ikede, B. O. (1972). Review of the pathology of domestic and laboratory animals caused by $T$. congolense, T. vivax, T. brucei, $T$. rhodesiense, and $T$. gambiense. Veterinary Pathology: 1-71

Musa, M. S., Abdelrasool, F. E., Elsheikh, E. A., Ahmed, L. A., Mahmoud, A. L. E. and Yagi, S.M. (2011). Ethnobotanical study of medicinal plants in the Blue Nile State, South Eastern Sudan. Journal of Medicinal Plants Research.5(17):42874297. www.academicjournals.org/ JMPR

Ogoti P, Esther M, Joanna A, Gabriel M, Mabel I, and Grace M. (2009) Evaluation of in vivo anti-trypanosomal activity of selected medicinal plant extracts. $J$ Med Plant Res 3: 850-854.

Olbrich, C., Gessner, A. and Kayser, O. (2002). Lipid-drug-conjugate (LDC) nanoparticles as novel carrier system for the hydrophilic antitrypanosomal drug diminazene diaceturate. Journal of Drug Target, 10(5):387-96.

Onyekwelu, N. A., (1999). Toxicity of existing trypanocides: A review. West African Journal of Pharmacology and Drug Research, 15(1 \& 2): 1 - 6 .

Raghunandan, D., Mahesh D. B, Basavarajac, S. B., Sawleb, S.Y., Manjunathd, A. V.(2010). Rapid biosynthesis of irregular shaped gold nanoparticle from macerated aqueous extracellular dried clove buds (Syzygium aromaticum) solution. Colloids Surf B: Biointerfaces79: 235 - 240.

Sheny, D.S., Mathew, J., and Philip, D. (2011). Phytosynthesis of $\mathrm{Au}, \mathrm{Ag}$ and $\mathrm{Au}-\mathrm{Ag}$ bimetallic nanoparticles using aqueous extract and dried leaf of Anacardium occidentale. Spectrochim. Acta A. 79: 254-262 
BAJOPAS Volume 14 Number 1, June, 2021

Shittu, K. O., Bankole, M. T., Abdulkareem, A, S., Abubakre, O. K. and Ubaka, A. U. (2017). Application of gold nanoparticles for improved drug efficiency. Advances in Natural Science: Nanoscience Nanotechnology8:035014 (8pp)

Sivaraman, S K., Elango, I., Kumar, S. and Santhanam, V. (2009). A green prorocol for room temperature synthesis of silver nanoparticles in seconds. Current Sci.97(7):1055 - 1059

Smitha, C., and Gopchandran, K. G (2013). Surface enhanced Raman scattering, antibacterial and antifungal active triangular and spherical gold nanoparticles. Spectrochimica Acta, Part A: Molecular and Biomolecular Spectroscopy (SAA), 102, 114-119.

Sofowora A (1993). Medicinal Plants and Traditional Medicines in Africal Chichester: Wiley) pp 97-145
Suliman, H. B. and Fieldman, B. F. (1989). Pathogenesis and aetiology of anaemia in trypanosomiasis with special reference to $T$. brucei and $T$. evansi. Protozoology Abstracts13: 37-45

Tor-Anyiin TA, Akpuaka MU, and Oluma HOA (2011). Phytochemical and antimicrobial studies on stem bark of Sterculia setigera, Del. Afr J Biotechnol.;10(53):11011-11015

Wang, F., Zhou, L., \& Gu, F. (2010). Characterization of anticancer hypocrellin A encapsulated with silica nanoparticles. Journal Thermal Analysis and Calorimetry, 102, 69-74

WHO, (1998). World Health Organization Control and Surveillance of African trypanosomiasis. A report of a WHO committee, Technical Report Series 881, I-VI, 1-114 Geneva. 